\title{
Interdisciplinary Collaborations in the Domain of Digital Libraries
}

\author{
디지털도서관 분야의 학제적 공동연구 분석에 관한 연구
}

EunKyung Chung*

\begin{abstract}
The domain of digital libraries is one of interdisciplinary fields since it contains various aspects of digital libraries. The main findings of digital library interdisciplinarity have been discussed in terms of contents, management and infrastructural technologies within the field of library and information science. The purpose of this study is to identify and widen the interdisciplinary structure of digital library domain by analyzing the collaborations from different disciplines. With 1,394 research articles of digital libraries from 1997 to 2010, the analysis of collaborations of authors from various disciplines was conducted. The results identified that three subject areas of authors such as Information science and library science, Computer science and Engineering were found as the centers to collaborate with various disciplines. In addition, sub-domains of digital library were recognized in terms of core digital library area, natural science area, medical related area and biology and medical area. The findings of this study depict the domain of digital libraries as a variety of subject areas since digital library domain is characterized with both research and practices.
\end{abstract}

\section{초 록}

디지털도서관 분야는 컨텐츠, 운영, 기반 기술 관련하여 다양한 분야를 포함하고 있는 학제적 학문분야 중 하나로 여겨진다. 이 연구의 목적은 기존의 문헌정보학 범주 내에서 파악되었던 디지털도서관의 하위분야 규명을 넘어서 다양한 학문 분야에서 다루고 있는 디지털도서관을 학제적 공동연구의 관점에서 분석하고자 하였다. 1997년부터 2010 년까지 게재된 디지털도서관 주제의 논문 1,394 편을 대상으로 다양한 분야의 공동저자 분석을 수행하였다. 그 분석결과 문헌정보학, 컴퓨터학, 공학 분야가 공동연구의 중심 역할을 수행하였음을 밝혔다. 또한 디지털도서관의 세부영역은 핵심디지털도서관영역, 자연과학영역, 의학관련 영역, 생물학 및 의학영역으로 파악되었다. 이러한 결과는 디지털도서관은 다양한 학문 분야에서 다루고 있으며, 이론중심의 연구뿐만 아니라 구축과 운영과 관련된 실무 영역이 함께 발전된 특징을 지니고 있기 때문인 것으로 파악되었다.

Keywords: digital libraries, co-author analysis, interdisciplinarity, domain analysis 디지털도서관, 공저자분석, 학제성, 도메인 분석

* Assistant Professor, Department of Library and Information Science, Ewha Womans University (echung@ewha.ac.kr)

- Received : 15 May 2011 - Revised : 24 May 2011 - Accepted : 3 June 2011

- Journal of the Korean Society for Information Management, 28(2): 37-51, 2011.

[DOI:10.3743/KOSIM.2011.28.2.037] 


\section{Introduction}

The concept of digital library is wide ranging since a variety of digital library practices and related research agendas have been approached since the 1990s (Borgman 1999). More than one disciplinary group has been involved in its various activities in the domain of digital libraries. According to Schwartz (2000), the definitions for digital library were identified 64 either formally or informally, as the concept of digital library is still evolving and composed of multi-dimensional aspects. The interdisciplinary characteristics of digital library are manifested in various ways such as contents and infrastructure (Liew 2009). Since the domain of digital library has appeared with increasing digital contents and technological infrastructures, several studies attempted to analyze the knowledge structure of digital library domain in various research methods (Borgman 1999; Lee, Kim, \& Kim 2010). Consequently, the digital library domain has been assumed as one of interdisciplinary fields since it contains various aspects such as library management expertise and technology related skills.

On the other hand, the interdisciplinary approaches to solve a wide variety of research problems have been employed since 1970's in terms of knowledge transfer across domain and integration (Qin, Lancster \& Allen 1997; Porter, Chohen, Roessner, \& Perrault 2007). As the interdisciplinary approaches in diverse disciplinary domains have been introduced and utilized, endeavors on identifying the interdisciplinarity or interdisciplinary domain analysis of digital library have been pursued. The efforts to identify the interdisciplinarity of domains can be applied to two primary categories. First, methodological approaches from the field of informetrics have been adopted to analyze the interdisciplinary domains (Morillo, Bordons, \& Gomez 2001). For instance, research methods such as citation analysis, co-authorship analysis, affiliation analysis, and co-word analysis have been used in order to identify interdisciplinary characteristics in various domains. In particular, since authors from a wide variety of disciplinary domains can be considered as a certain level of interdisciplinarity, affiliation information of authors has been approached in terms of analyzing the interdisciplinary domains and identifying the interdisciplinarity of digital libraries (Chen \& Huang 2007; Cronin \& Meho 2008). Second, specific disciplinary areas have been recognized and studied as interdisciplinary domains. As disciplinary areas such Engineering, Genetics and Cognitive Science have been studied by researchers, they have been distinguished as representative interdisciplinary disciplines (Lui \& Wang 2005; Rinia, van Leeuwen, \& van Raan 2005; Schunn, Crowley, \& Okada 1998; Tijssen 1992).

As pointed out in related studies (Borgman 1999; Chung 2010), the digital library domain is composed not only of research-oriented papers, but of such practices-focused papers as digital library building and implementation issues. In order to identify the domain of digital library in a wide sense, the purpose of this study is to investigate the interdisciplinarity of digital library by analyzing the articles published in the journals of the Web of Science, which is not 
limited in specific areas, over 14 years from 1997 to 2010. More specifically, for this study, the interdisciplinarity is regarded as the collaborations of co-authors from different disciplines. As Qin, Lancaster and Allen (1997) pointed out with empirical data, the interdisciplinarity is contributed considerably by collaborations by authors from different disciplines. The collaborations from different disciplinary areas are utilized to recognize the interdisciplinary structure and characteristics of digital library domain of this study. Based on the knowledge structure of digital library domain identified in this study, the findings of this study will be able to develop and manage proper journals and subject area collections for digital library researchers and professionals.

\section{Related studies}

\subsection{Digital library domain}

The reviews on the domain of digital library (Chung 2010; Liew 2010) pointed out that the domain of digital library has been implemented in mid 1990s and is still evolving in terms of research and concepts. The practices and concepts of digital library are identified in a wide variety of ranges including technology, collections, information organization, user services and social and economic aspects. Liew (2007) reviewed the domain of digital library research from 1997 to 2007. Liew analyzed 577 articles from primary peer-reviewed library and information science journals reflecting both academic and practical per- spectives on digital libraries. While the dominant topics in digital library research are digital library use and usability, organizational and economic issues and legal issues, there is little research on ethical issues and social/cultural issues. The three years of 2004, 2005 and 2006 are recognized as the most productive in terms of digital library research production. The D-Lib Magazine is found the top journal issuing digital library research. By using informetrics methodology, through co-authorship networks, Liu, Bollen, Nelson and Van de Sompel (2005) analyzed the digital library domain in terms of validating and refining of PageRank and AuthorRank. For this analysis, they used a data set comprising the conference papers of ACM, IEEE, and joint ACM/IEEE digital library conferences (JCDL) from 1994 to 2004. While the domain of digital library is still evolving and enriches the networks of collaboration common in other areas of disciplines, the authors in digital library domain collaborate closely within specific clusters restricting their collaborations to specific groups of interests. On the other hand, from the view of library and information science, Lee, Kim and Kim (2010) analyzed the digital library research domain using 54 journals from 1994 to 2008. Using profiling, parallel nearest neighbor clustering and cluster-based network methods, they recognized three phases of digital library research domain. While the first phase are dedicated to the fundamental research including electronic media keywords, the second and the third phase emphasize more on topics including user studies and metadata, respectively. 


\subsection{Interdisciplinarity}

While the interdisciplinary research and collaborations with different disciplinary domains have been considered as promising and heavily promoted by funding agencies, the definition of interdisciplinarity has been viewed one of slippery delineations. Since it contains multiple meanings and applications, according to the classification provided by Qin, Lancaster and Allen (1997) there are eight perspectives proposed by numerous researchers on interdisciplinarity: first, the knowledge from multiple disciplinary domains is combined in a single research, second, group members use different approaches in attempting to solve problems, third, group members perform different roles in solving problems, fourth, several individual members work on a common problem, fifth, there is an expectation for group responsibility for the final product, sixth, group members share common facilities and equipment, seventh, the nature of problem determines the selection of group members, and eighth, members are influenced by how others perform their tasks. While the identification on interdisciplinarity was conducted more conceptually, one of major empirical attempts to measure the interdisciplinarity of science was conducted by Porter and Rafols (2009). Porter and Rafols investigated the degree of interdisciplinarity by using an integration score index for six disciplines, Biotech, EE, Math, Med R\&E, Neuroscience and Physics between 1975 and 2005. Although there are slight differences among six disciplinary domains, science is becoming more interdisciplinary but taking slow steps. More specifically, Porter and Rafols identified that research knowledge transfer using citation analysis was found primarily in neighboring fields. On the other hand, by using journals' multi-assigned subject categories, Morillo, Bordons and Gomez (2003) presented a topology of disciplines and research areas according to the degree of interdisciplinarity. Four clusters of subject categories of journals were identified in terms of interdisciplinarity.

In general, the concept of interdisciplinarity contains multiple aspects in terms of various dimensions in it. The manifestation of interdisciplinarity mainly depends on how to conceptualize the phenomenon. In a way of viewing the interdisciplinarity, there are two approaches: collaboration-based and citationbased. First, in order to investigate the interdisciplinarity of disciplines, the collaborations of authors and co-authoring patterns are analyzed primarily from the affiliation information. On the other hand, the citationbased approaches can be utilized to identify the interdisciplinarity of disciplines through knowledge transfer using citation analysis and relevant measurements. For this study, the collaboration-based approach is adopted to investigate the interdisciplinarity of digital library domain.

\section{Methodology}

\subsection{Data set}

The data set for this study was searched from the ISI Web of Science database using a keyword, 
"digital librar*" in the topic field. The search was specified in terms of all years in timespan, English in language, research article in document type. A total of 1,394 research articles were collected when using the specified features. The search was conducted in December of 2010.

In terms of identifying the interdisciplinarity, the affiliation information of authors was recognized. The affiliation information was extracted from the data set using the Bibexel, an open source software for bibliometric analysis. In general, typical affiliation information includes institution and department's names. The extracted affiliation names were categorized according to the subject categories (SC) provided in the Thomson Reuters. The subject categories were located from three indices, Science Citation Index, Social Science Citation Index and Art and Humanities Index. When the subject categories consist of more than one hierarchical class, the upper classes were used rather than lower classes in order to classify author's affiliation in a broader sense. For instance, as "Computer Science" is an upper class and "Information Systems" is a lower class belonging to the upper class in the Science Citation Index, the classification was conducted as "Computer Science" in order to avoid the scattered subject area distribution based on author's affiliation.

\subsection{Analysis methods}

In order to analyze the interdisciplinarity of digital library domain, primarily two methodological attempts were employed with descriptive and temporal accounts. First, the network analysis of subject categories of authors' affiliation was utilized. For the tool for analyzing the network among subject categories, the NodeXL, an open software tool for network analysis, was used for this data set. On the other hand, the multidimensional scale analysis to characterize the digital library domain, the PROXSCAL algorithm of the multidimensional scaling (MDS) provided by SPSS 18 was used. For the MDS, the data were processed with the standard $z$ values from Pearson's $r$ according to the findings by Lee (2007).

\section{Results}

\subsection{Overall characteristics of digital library domain}

Overall article trends over 14 years in the area of digital library research are as shown in Figure 1. The first paper in the ISI Web of Science database including the Science Citation Index, Social Science Citation Index occurred in 1997. As indicated, digital library domain between 1997 and 1999 has been increased drastically and is similar to the findings of related studies. While there are only ten articles in 1997, the number of articles has been increased as 66 articles in 1998 and 107 articles in 1999, respectively. After having a sharp increase from 1997 to 1999 , research in digital library domain has experienced slight ups and downs from 2000 to 2004 for adjusting. The number of articles for this period is between 109 and 88 articles. After the period of 
42 Journal of the Korean Society for Information Management, 28(2), 2011

adjustment, during the period between 2005 and 2010 , the research on digital libraries has been produced steadily. The average number of articles on digital library research is 122.5 per year and the slop may indicate a slight decline in terms of number of articles since 2008 .

For a total of 1,394 research articles, there were 491 journals involved. Among 491 journal list, the top 20 journals were shown in Table 1 in order to present the influential journals.

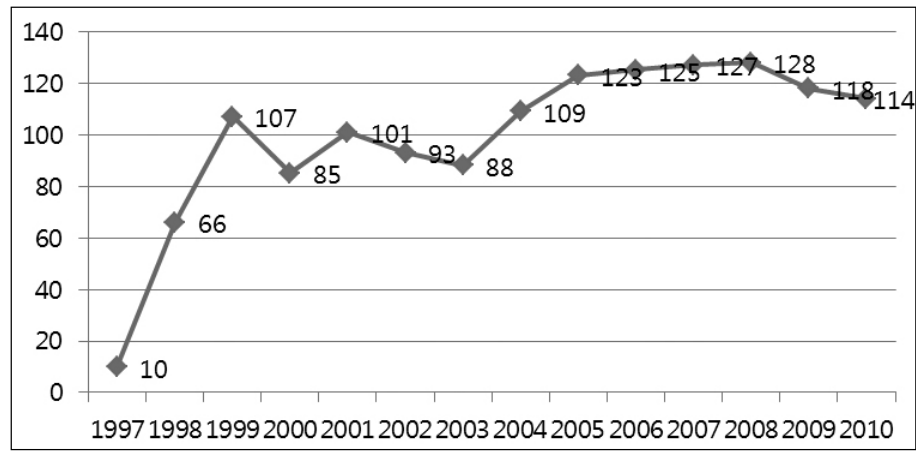

〈Figure 1〉 Overall research production from 1997 to 2010

〈Table 1〉 Top 20 journal list for digital library domain

\begin{tabular}{l|c}
\hline \multicolumn{1}{c}{ Journal Title } & Freq. \\
\hline $\begin{array}{l}\text { Journal of the American Society for Information Science and Technology } \\
\text { (Previously, Journal of the American Society for Information Science) }\end{array}$ & 98 \\
\hline Program-Electronic Library and Information Systems & 66 \\
\hline Information Processing \& Management & 61 \\
\hline Information Technology and Libraries & 57 \\
\hline Online Information Review & 55 \\
\hline Communications of The ACM & 26 \\
\hline Journal of Information Science & 24 \\
\hline Aslib Proceedings & 23 \\
\hline Monthly Notices of The Royal Astronomical Society & 19 \\
\hline Multimedia Tools and Applications & 19 \\
\hline Computer & 17 \\
\hline IEEE Transactions on Very Large Scale Integration (Vlsi) Systems & 13 \\
\hline IEEE Transactions on Computer-Aided Design Of Integrated Circuits And Systems & 11 \\
\hline IEEE Transactions on Knowledge And Data Engineering & 11 \\
\hline Journal of Digital Imaging & 10 \\
\hline Astrophysical Journal & 10 \\
\hline IEEE Transactions on Multimedia & 10 \\
\hline Multimedia Systems & 10 \\
\hline Scientometrics & 10 \\
\hline International Journal on Document Analysis and Recognition & 9 \\
\hline
\end{tabular}


The top 20 journals for digital library articles appeared as a total of 559 times, which is more than one third of the total number of articles. Most frequently appeared journal was found as Journal of the American Society for Information Science and Technology (Previously, Journal of the American Society for Information Science). Along with the JASIS (T), the top journals in this list can be classified primarily into Information science and library science, and Computer science and Engineering.

As 4,184 authors were fond as a total number of authors for this data set and, approximately three authors on average contribute a single article in terms of co-authorship. Among 4,184 authors, the affiliations of 3,116 authors were identified, which is $76 \%$. From those identified affiliations, 105 unique subject categories from SCI, SSCI and A\&HI were recognized. The subject categories most frequently found based on author's affiliation information are shown in Table 2. Three top subject categories, Information \& Library Science, Computer Science and Engineering were found 620 times, 545 times and 445 times, respectively. Those three subject categories consist of a total of 1,610 in the frequency which corresponds to more than half of the total frequency of subject categories from authors' affiliation. Consequently, the frequency distribution of 105 subject categories can be understood as highly diverse from Information science \& Library science (freq. of 620) to Anthropology (freq. of 4). For analysis of co-authorship of subject categories, among 3,116 subject categories from affiliation information, repeated subject categories in a single article were deleted. For instance, when an article was co-authored from three authors and among three authors, there are two authors from Information science \& library science and one author from Computer science, the co-authoring information with subject categories counted one in Information science and library science and one in Computer science, respectively. After processing the repeated subject categories in a single article, a total number of frequencies of subject categories for this data set are 1,841 .

〈Table 2〉 Top ten subject categories from author affiliation information

\begin{tabular}{c|l|c}
\hline Rank & \multicolumn{1}{|c}{ Subject category } & No. of freq. \\
\hline 1 & Information science \& library science & 620 \\
\hline 2 & Computer science & 545 \\
\hline 3 & Engineering & 445 \\
\hline 4 & Astronomy \& Astrophysics & 306 \\
\hline 5 & Medicine & 131 \\
\hline 6 & Genetics \& heredity & 109 \\
\hline 7 & Oncology & 64 \\
\hline 8 & Health care sciences \& services & 53 \\
\hline 9 & Physics & 48 \\
\hline 10 & Radiology & 47 \\
\hline
\end{tabular}


44 Journal of the Korean Society for Information Management, 28(2), 2011

\subsection{Collaborations from different disciplines}

In order to investigate the interdisciplinarity of digital library domain, the characteristics of authors' collaborations from various disciplines were analyzed. The authors' affiliations were identified in terms of subject categories provided by the ISI. Since 80 subject categories occurred more than twice among 105 subject categories recognized, 80 categories were selected for analysis. The co-authoring pairs of subject categories were identified as 381 pairs. The maximum number of frequency is 77 while the minimum number of frequency is 1 . The pairs of subject categories with more than six times of frequency are indicated as shown in Table 3. As shown in Table 3, the pair of Computer science and Information science $\&$ Library science was found most (77 times) followed by the pair of Computer Science and Engineering (59 times) and the pair of Engineering and Information science \& library science (24 times). This result indicates top three subject areas of collaborations for digital library domain in terms of frequencies.

On the other hand, the pairs of subject categories are indicated in terms of cosine values in Table 4. The cosine values were found between 0.577 and 0.005. The pair of Physiology and Psychiatry was found most which is 0.577 , while three pairs of subject categories were 0.005 such as Information science \& library science and Oncology, Astronomy \& astrophysics and Computer science and Astronomy $\&$ astrophysics and Information science \& library

〈Table 3〉 The frequency of collaborations between subject categories

\begin{tabular}{l|l|c}
\hline \multicolumn{1}{c|}{ Subject category } & \multicolumn{1}{c}{ Subject category } & freq. \\
\hline Computer science & Information science \& library science & 77 \\
\hline Computer science & Engineering & 59 \\
\hline Engineering & Information science \& library science & 24 \\
\hline Astronomy \& astrophysics & Physics & 13 \\
\hline Health care sciences \& services & Medicine & 12 \\
\hline Genetics \& heredity & Oncology & 11 \\
\hline Biotechnology \& microbiology & Genetics \& heredity & 9 \\
\hline Business & Information science \& library science & 8 \\
\hline Medicine & Radiology & 8 \\
\hline Biotechnology \& applied microbiology & Medicine & 7 \\
\hline Education & Information science \& library science & 7 \\
\hline Computer science & Medicine & 7 \\
\hline Computer science & Mathematics & 7 \\
\hline Biotechnology \& applied microbiology & Genetics \& heredity & 7 \\
\hline Genetics \& heredity & Pathology & 6 \\
\hline Information science \& library science & Medicine & 6 \\
\hline Engineering & Medicine & 6 \\
\hline Medicine & Pediatrics & 6 \\
\hline
\end{tabular}


$\langle$ Table 4$\rangle$ The cosine values of collaborations between subject categories

\begin{tabular}{l|l|c}
\hline \multicolumn{1}{c|}{ Subject category } & \multicolumn{1}{c}{ Subject category } & COS \\
\hline Physiology & Psychiatry & 0.577 \\
\hline Mathematical \& computational biology & Virology & 0.577 \\
\hline Food science \& technology & Soil science & 0.577 \\
\hline Infectious diseases & Virology & 0.500 \\
\hline Law & Social work & 0.500 \\
\hline Area studies & Microbiology & 0.408 \\
\hline Gastroenterology \& hepatology & Pathology & 0.365 \\
\hline Management & Social work & 0.354 \\
\hline Horticulture & Soil science & 0.333 \\
\hline Ophthalmology & Virology & 0.333 \\
\hline Plant sciences & Soil science & 0.320 \\
\hline Horticulture & Plant sciences & 0.320 \\
\hline Neuroimaging & Psychology & 0.289 \\
\hline Infectious diseases & Mathematical \& computational biology & 0.289 \\
\hline Pharmacology \& pharmacy & Toxicology & 0.267 \\
\hline Linguistics & Mathematical \& computational biology & 0.258 \\
\hline Gastroenterology \& hepatology & Surgery & 0.250 \\
\hline Environmental sciences & Meteorology \& atmospheric sciences & 0.250 \\
\hline & &
\end{tabular}

science. The high values in cosine indicate that the pair of two subject categories occurred frequently with each other, rather than either one subject category was combined with any other subject categories. This pattern can be found in less occurred subject categories than more appeared subject categories. For instance, the pairs of Physiology and Psychiatry, Mathematical \& computational biology and Virology and Food science \& technology and Soil science occurred in less than 3 times in frequencies, respectively. This result presents that some pairs of collaborations in terms of subject categories tend to collaborate with each other more, especially when the pairs do not occur frequently in terms of collaborations. Whereas three major subject categories of Information science and library science, Computer science and Engineering, tend to collaborate with authors from various subject categories.

\subsection{Network overview of collaborations}

The overall network with subject categories was identified using the NodeXL package. The overall network density is 0.097 which is extremely sparse. In order to present the network with more visibility, the strength of links between nodes were selected with more 0.2 as shown in Figure 2. The size of nodes and links is presented relatively. The size of nodes represents the degrees of nodes, as the strength of links shows the frequency of links. Five noticeable nodes such as Computer science, Information science \& library science, Engineering, Genetics \& heredity 


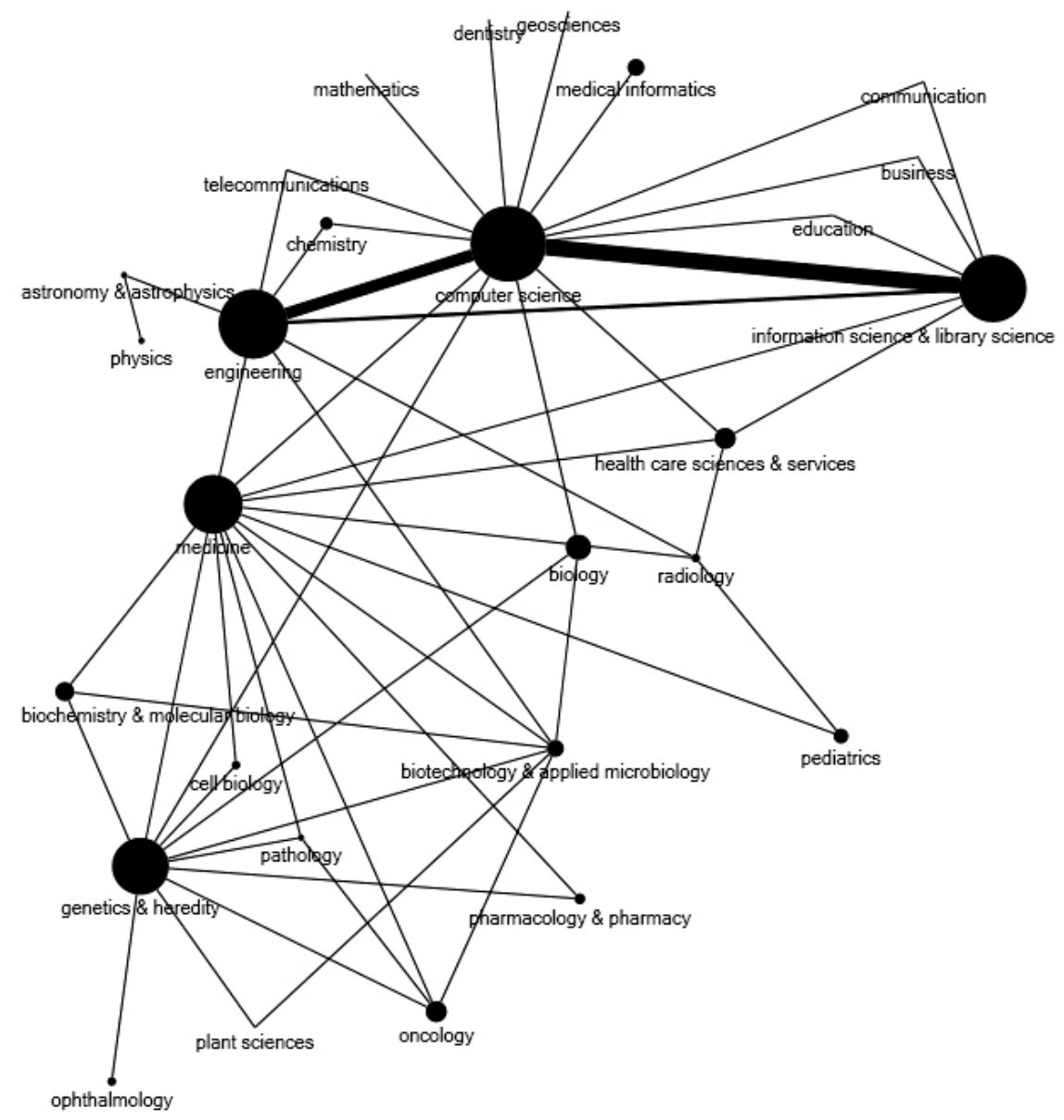

〈Figure 2〉 The network of collaboration in digital library domain

and Medicine can be recognized. Among these five nodes, the pairs of Computer science and Information science \& library science and Engineering and Computer science, are shown to be primary in digital library domain. Computer science subject area links to the areas of Engineering and Information science \& library science. Each of these primary subject areas indicates some characteristics. First, Information science \& library science tends to bridge the subject areas which are connected to other subject areas. For instance, the direct nodes to Information science \& library science such as Communication, Business, Education, and Health care science \& services are connected to other subject categories. In other words, while the pair of Computer science and Information science \& library science is strongly connected with each other, it is through related subject categories as well. Second, Computer science plays a bridging role in connecting Engineering and Information science and library science. While it connects 
with two primary subject areas, Computer science contains some leaf-type nodes such as Mathematics, Dentistry, Geoscience and Medical informatics. Third, similarly to the subject area of Computer science, as Engineering subject area is connected to primary subject areas as well, it contain a leaf-type node, Astronomy \& Astrophysics. Fourth, the subject areas of Medicine and Genetics \& heredity share related subject areas, Biochemistry \& molecular biology, Biotechnology \& applied microbiology, Cell biology, Pathology Pharmacology \& pharmacy.

In addition, the subject categories are ranked in terms of centrality measures as shown in Table 5. In terms of degree centrality, Computer science, Engineering, Information science \& library science, Medicine, and Genetics \& heredity are highly ranked. While the betweenness centrality provides a similar pattern to the degree centrality distribution, Engi- neering is ranked first in terms of betweenness centrality followed by Computer science and Information science \& library science. While in terms of closeness centrality, the distribution pattern is similar to the degree and betweenness centrality, Health care sciences \& services dropped five and Pharmacology \& pharmacy is up by three steps compared to the degree centrality. As shown in Figure 2 and Table 5, while the subject categories with high degree centrality are high in betweenness centrality, there exist slight distinctions. For instance, subject categories such as Engineering, Genetics \& heredity and Medical informatics are slightly better in terms of betweenness centrality. In other words, these subject categories are good at connecting other subject categories through themselves. On the other hand, several subject categories marginally improve, for instance Computer science, Medicine, Health care sciences \& services,

〈Table 5〉 Subject categories according to centrality measures

\begin{tabular}{l|c|c|c|c}
\hline \multicolumn{1}{c|}{ Subject category } & Degree & Rank & Betweenness & Rank \\
\hline Computer science & 45 & 1 & 699.0462 & 2 \\
\hline Engineering & 42 & 2 & 836.9349 & 1 \\
\hline Information science \& library science & 41 & 3 & 663.5785 & 3 \\
\hline Medicine & 37 & 4 & 488.3616 & 5 \\
\hline Genetics \& heredity & 36 & 5 & 497.2229 & 4 \\
\hline Biology & 21 & 6 & 243.5649 & 6 \\
\hline Health care sciences \& services & 19 & 7 & 110.3157 & 9 \\
\hline Oncology & 19 & 8 & 143.7414 & 8 \\
\hline Imaging science \& photographic technology & 19 & 9 & 150.9865 & 7 \\
\hline Biochemistry \& molecular biology & 18 & 10 & 76.08468 & 11 \\
\hline Biotechnology \& applied microbiology & 17 & 11 & 60.93316 & 12 \\
\hline Medical informatics & 17 & 12 & 105.6323 & 10 \\
\hline Pediatrics & 16 & 13 & 34.02477 & 14 \\
\hline Chemistry & 15 & 14 & 45.01517 & 13 \\
\hline Pharmacology \& pharmacy & 14 & 15 & 19.38588 & 15 \\
\hline
\end{tabular}


Biochemistry \& molecular biology, Biotechnology \& applied microbiology and Pediatrics.

Consequently, the domain of digital library in terms of collaborations of authors from various subject categories can be understood as five distinctive primary subject areas and its relationships to other subject areas. As the subject categories such as Computer science, Engineering, Information science \& library science, Medicine and Genetics \& heredity, are primary areas in digital libraries research domain, they play important roles in connecting other subject areas.

\subsection{Dimensional analysis of collaborations}

In a view of the dimensional perspective on digital library domain, the dimensional analysis was conducted by using the PROXSCAL algorithm of multidimensional scaling (MDS) provided by SPSS 18. From the MDS analysis, the dimensions were recognized as shown in Figure 3. The dimensions of digital library domain can be categorized into four areas in Figure 3. First, core digital library area, which is located at the top left, contains primary subject categories such as Engineering, Computer science and Information science and library science. While three subject categories were recognized as the centers of connecting other subject categories, they were classified with mainly subject categories of social science. In addition, core digital library area can be noted that the density of it is found relatively high. Second, on the left bottom, a natural science area can be found. The natural science area can be

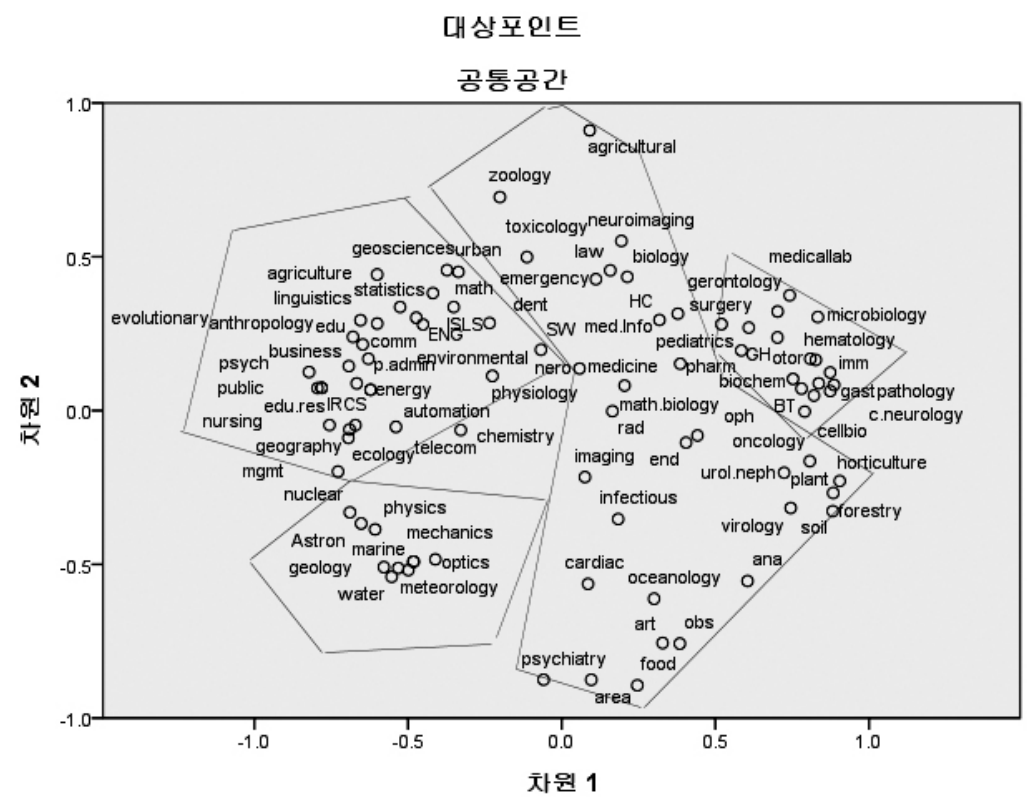

〈Figure 3〉 Dimensions of collaboration in digital library domain 
distinguished into two areas. One contains Physics, Nuclear and Mechanics and the other includes Optics, Geology, Marine science, Water science and Meteorology. Third, medical related area can be recognized on the far right. It contains subject categories such as Medical laboratory, Surgery, Biotechnology, Biochemistry, Immunology and so on. Fourth, in the middle, biological and medical area contains various subject categories scattered in this area from Area studies to Agriculture. The density of biological and medical area is highly sparse. In this dimensional analysis, the domain of digital libraries indicates that active collaborations with a wide variety of disciplines have occurred.

\section{Conclusion}

As one of interdisciplinary domains, digital library domain was explored by analyzing the collaborations of authors from different disciplines. The domain of digital libraries was analyzed in a wide sense, rather in a single specific discipline. With analyzing a dataset of 1,394 research articles, the digital library domain was recognized in terms of interdisciplinarity. The results of analysis present three perspectives on digital library domain. First, the diversity of collaborations of authors from subject categories is wide ranging. Compared to the previous studies of digital library domain analysis (Lee, Kim, \& Kim 2010; Liu, Bollen, Nelson, \& Van de Sompel 2005), a wide variety of subject areas from medical area to agriculture are found in this current study. Primarily, the reason for the diversity of this study can be linked to the concept of digital libraries. In general, the fundamentals of the digital libraries include related issues on practices such as building, maintaining and aggregating, as well as research-oriented themes. For this current study, the dataset was designed to collect articles if they are relevant in terms of the topic, digital libraries, without limiting in specific disciplines such as information science and library science. Rather, this study includes all research articles in a wide variety of disciplines. The research articles in seemingly remote areas from digital library research, for instance Agriculture, and Neurosciences, are mostly on the practices of digital library. Hence, the findings of this study present that it results in depicting the domain of digital libraries with both perspectives: practices-bound and research-oriented. Second, core disciplines of digital library domain are recognized, Information science and library science, Computer science and Engineering. These three subject areas are on the center with connecting and bridging various subject categories. Third, four distinctive dimensions are found by using the multidimensional scaling such as core digital library area, medical related area, natural science area and biology and medical area. Among four areas, core digital library area contains three core subject categories, Information science and library science, Computer science and Engineering, found in the network analysis and highly dense. On the other hand, medical related area and natural science area are dense as well, but they lack the highly connected subject categories. Since the last area is mainly on biology 
and medical area and they do not contain some coherent subject categories, it is highly scattered in the dimension area.

Some limitations should be noted for future research. The first limitation relates to the data samples which was searched using "digital library*". While the term, digital libraries, has been established in the sense of referring to what we can agree on, it was not the case in the mid-1990s. In the period of the mid-1990s, more common terms for digital libraries were electronic or virtual libraries. Since this data set might not include some early studies, the data might have skewed the study results. Second, one of the findings recognizes two distinctive aspects such as research-oriented and practices-bound aspects. Since this study is to investigate the digital library domain in a wide context, some future studies need to be pursued for a clear picture of it. This study investigated the interdisciplinarity of digital library domain by utilizing the collaborations of authors from various subject categories through the network analysis and the multidimensional scaling. While primary core subject areas such as Information science and library science, Computer science and Engineering are found, the results of analysis identify that the domain of digital library is mainly diverse. One of sensible reasons for the diversity is that the domain of digital library is composed of two major aspects which are research-oriented and practices-bound. For the research of digital libraries, subject areas such as Information science and library science, Computer science and Engineering are mainly identified. On the other hand, for the practices of digital libraries, various applications of digital libraries were pursued in a wide variety of subject areas such as Agriculture and Psychology.

\section{References}

Borgman, C. L. 1999. "What are digital libraries? Competing visions." Information Processing \& Management, 35: 227-243.

Chen, C. R. and Y. Huang. 2007. "Author affiliation index, finance journal ranking and the pattern of authorship." Journal of Corporate Finance, 13: 1008-1026.

Chung, E. 2010. "Digital Libraries.” In M.J. Norton (Ed.), Introductory Concepts in Information Science. New Jersey: American Society for
Information Science and Technology, 117-130.

Cronin, B. and L. I. Meho. 2008. "Applying the author affiliation index to Library and Information Science journals." Journal of the American Society for Information Science and Technology, 59(11): 1810-1818.

Lee, J. Y. 2007. “A comparison analysis of various approaches to multidimensional scaling in mapping a knowledge domain's intellectual structure." Journal of the Korean Society for 
Information Management, 41(2): 335-357.

Lee, J. Y., H. Kim, and P. J. Kim. 2010. "Domain analysis with text mining: Analysis of digital library research trends using profiling methods." Journal of Information Science, 36(2): 144-161.

Liu, X., J. Bollen, M. L. Nelson, and H. Van de Sompel. 2005. "Co-authorship networks in the digital library research community." Information Processing \& Management, 41: 1462-1480.

Liew, C. L. 2009. "Digital library research 1997-2007: organizational and people issues." Journal of Documentation, 65(2): 245-266.

Lui, Z. and C. Wang. 2005. "Mapping interdisciplinarity in demography: a journal network analysis." Journal of Information Science, 31: 308-316.

Morillo, F., M. Bordons, and I. Gomez. 2001. "An approach to interdisciplinarity through bibliometric indicators." Scientometrics, 51(1): 203222.

Morillo, F., M. Bordons, and I. Gomez. 2003. "Interdisciplinarity in Science: A tentative typology of disciplines and research areas." Journal of the American Society for Information Science and Technology, 54(13): 1237-1249.

Porter, A. L., A. S. Chohen, D. Roessner, and M.
Perrault. 2007. "Measuring researcher interdisciplinarity." Scientometrics, 72(1): 117-147.

Porter, A. L. and I. Rafols. 2009. "Is science becoming more interdisciplinary?: measuring and mapping six research fields over time." Scientometrics, 81(3): 719-745.

Qin, J., F. W. Lancaster, and B. Allen. 1997. "Types and levels of collaboration in interdisciplinarity research in the sciences." Journal of the American Society for Information Science, 48(10): 893-916.

Rinia, E. J., T. N. van Leeuwen, and A. F. J. van Raan. 2002. "Impact measures of interdisciplinary research in physics." Scientometrics, 53(2): 241-248.

Schunn, C. D., K. Crowley, and T. Okada. 1998. "The growth of multidisciplinarity in the cognitive science society." Journal of Documentation, 64(3): 319-332.

Schwartz, C. 2000. "Digital libraries: an overview." The Journal of Academic Librarianship, 26(6): 385-393.

Tijssen, R. J. W. 1992. “A qualitative assessment of interdisciplinary structures in science and technology: co-classification analysis." Research Policy, 21: 27-44. 